\title{
RANTAI PASOK BERAS PADA BULOG BERBASIS NEURAL NETWORK
}

\author{
Muhammad Imam Ghozali \\ Fakultas Teknik, Program Studi Teknik Informatika \\ Universitas Muria Kudus \\ Email: imam.ghozali@umk.ac.id
}

\begin{abstract}
ABSTRAK
Sebagai lembaga terpenting dalam menjaga ketahanan pangan di Indonesia, perusahaan umum (Perum) Badan urusan Logistik (BULOG) sejak didirikannya memiliki tugas memasok bahan pangan, sehingga pengetahuan dan pengalaman BULOG dalam manajemen rantai pasok pangan dan hasil pertanian lainnya seyogianya dapat diandalkan. Namun BULOG belum teruji dalam perspektif masih menghadapi berbagai permasalahan yang sangat kompleks, yang muncul mulai dari masalah pasokan gabah di level petani, proses penggilingan gabah di level industri penggilingan (miller), hingga proses distribusi beras ke level konsumen. Dengan demikian, sebagai komoditas pangan utama, permasalahan beras bukan hanya merupakan permasalahan ekonomi saja tetapi juga bersifat politis. Data mining dapat membantu dalam memprediksi suatu sistem, sehingga dapat dilakukan pada penelitian ini agar prediksi lebih tepat dan akurat. Penelitian ini teknik yang dipakai ialah neural network backpropagation, ada beberapa tahap dalam peneilitian ini yaitu tahap pengumpulan data historik, pengolahan data, model atau metode yang diusulkan, eksperimen pada model tersebut, evaluasi dan validasi hasil. Pada hasil analisa menunjukan bahwa model ini mempunyai tingkat kesalahan atau error yang kecil atau didalam backpropagation sering disebut dengan mean square erorr (MSE). Disimpulkan bahwa teknik data mining menggunakan neural network backpropagation dapat menghasilkan suatu nilai error yang minimal sehingga tepat dan akurat untuk menentukan jumlah pasokan beras pada tahun berikutnya.
\end{abstract}

Kata kunci: pasok beras, supply chain, data mining, neural network backpropagation, mean square erorr.

\begin{abstract}
As the most important institutions in maintaining food security in Indonesia, a general (Housing) affair Logistics Agency (Bulog) since its inception has the task of supplying food, so that the knowledge and experience in supply chain management BULOG food and other agricultural products should be reliable. However, BULOG untested in perspective still faces various problems that are complex, ranging from problems arising at the level of farmers' grain supply, grain milling process at the level of the milling industry (miller), until the rice distribution to the consumer level. Thus, as the main food commodities, rice is not only a problem of economic problems but also political. Data mining can help in predicting the system, so it can be done in this study to be more precise and accurate predictions. For this study are the techniques used Backpropagation Neural Network, there's some stage in the stage Extensive historical data collection, data processing, or the model proposed method, experiments on the model, evaluation and validation of the results. In research results of the analysis show that this model has an error rate or a small error in the backpropagation or often called the mean square erorr (MSE). It was concluded that data mining techniques using backpropagation neural network can generate an error value is minimal so precise and accurate way to determine the amount of supply of rice in the next year.
\end{abstract}

Keywords: rice supply chain, supply chain, data mining, neural network backpropagation, mean Square error.

\section{PENDAHULUAN}

Sebagai lembaga terpenting dalam menjaga ketahanan pangan di Indonesia, perusahaan umum (Perum) badan urusan logistik (BULOG) sejak didirikannya memiliki tugas memasok bahan pangan, sehingga pengetahuan dan pengalaman badan urusan logistik (BULOG) dalam manajemen rantai pasok pangan dan hasil pertanian lainnya seyogianya dapat diandalkan.

Adanya demand atau permintaan merupakan langkah awal terjadinya aktifitas logistik. Secara konsep, siklusnya berjalan dari bawah ke atas turun lagi ke bawah, maksudnya adalah adanya permintaan akan diteruskan terhadap elemen produsen, dan diteruskan lagi terhadap elemen supplier bahan baku, kemudian rantai tersebut mulai bergerak ke bawah lagi, dari supplier - produsen - konsumen kembali. 
Dalam penelitian ini, kegiatan forecasting tersebut dilakukan karena adanya permintaan atas kebutuhan beras yang terus berkesinambungan dari tahun ke tahun dengan jumlah yang sangat signifikan, terutama di daerah dengan kepadatan penduduk yang tinggi, daerah rawan bencana dan daerah yang bukan merupakan lumbung padi atau surplus beras. Oleh karena itu dibutuhkan analisa ke depan sebagai antisipasi awal.

Peramalan dengan pendekatan metode analytical hierarchi process (AHP) memiliki kelemahan yaitu tidak adanya pengujian secara statistik sehingga tidak ada batas kepercayaan dari model yang terbentuk dan ketergantungan dari input utamanya. Input utama ini berupa persepsi seorang sehingga dalam hal ini melibatkan subyektifitas selain itu juga model menjadi tidak berarti jika seseorang tersebut memberikan penilaian yang keliru.

Dari penelitan yang pernah ada dengan judul sistem pasokan sayuran ke ritel modern yang melakukan pendekatan metode analisis deskriptif memiliki kelemahan yaitu Pengamatan pada subjek studi hanya dilakukan satu kali yang dapat diibaratkan sebagai "potret" hingga tidak dapat diketahui perubahan yang terjadi dengan berjalannya waktu, Selain itu apabila ditemukan suatu masalah, kita tidak dapat menentukan sebab-akibatnya.

Dengan metode artificial neural network (Jaringan Syaraf Tiruan) yang diterapkan dalam salah satu aktifitas logistik, yaitu peramalan (forecasting), maka prediksi pemenuhan kebutuhan (demand) masyarakat akan Beras diharapkan dapat diselesaikan dengan optimal dikarenakan sifat dari metode ini yang fleksibel tanpa perlu mengklasifikasikan atau menginterpretasikan terlebih dahulu pola data historik yang ada. Fleksibelitas metode artifical neural network (ANN) itu disebabkan oleh keunggulan metode ini yang dapat mengenali pola suatu data historik pada saat pembentukan jaringannya dengan cara proses pembelajaran dan pelatihan (self learning). Lebih tepatnya metode neural network (Jaringan Syaraf Tiruan) yang diterapkan adalah backpropagation.

\subsection{Konsep Supply Chain Management (SCM)}

Konsep supply chain merupakan konsep baru dalam melihat persoalan logistik. Konsep lama melihat logistik sebagai persoalan itern masing-masing perusahaan dan pemecahannya di titik beratkan pada pemecahan secara intern diperusahaan masing-masing. Dalam konsep baru ini, masalah logistik dilihat sebagai masalah yang lebih luas dan terbentang sangat panjang mulai dari bahan baku sampai produk jadi yang digunakan oleh konsumen akhir [5][9][10][12]. Konsep rantai pasok yang relatif baru sebetulnya tidak sepenuhnya baru karena konsep tersebut merupakan perpanjangan dari konsep logistik. Hanya manajemen logistik lebih terfokus pada pengaturan aliran di dalam suatu perusahaan, sedangkan manajemen rantai pasok menganggap bahwa integrasi dalam suatu perusahaan tidaklah cukup. Integrasi harus dicapai untuk seluruh mata rantai pengadaan barang, mulai dari yang paling hulu sampai dengan yang paling hilir [12][14].

Oleh karena itu, rantai pasok terfokus pada pengaturan aliran barang antar perusahaan yang terkait, dari hulu sampai hilir bahkan sampai pada konsumen terakhir. Perbedaan dari manajemen logistik dan manajemen rantai pasok dapat dilihat pada Tabel 1 [7].

Tabel 1. Perbedaan manajemen logistik dan manajemen rantai pasok

\begin{tabular}{ll}
\hline Manajemen Logistik & Manajemen Rantai Pasok \\
\hline Mengutamakan pengelolaan, termasuk arus barang & Mengutamakan arus barang antar perusahaan, \\
dalam perusahaan. & dari yang paling hulu sampai yang paling hilir. \\
Berorientasi pada perencanaan dankerangka kerja & Atas dasar kerangka kerja,mengusahakan \\
menghasilkan rencana tunggal arus barang & hubungan dan koordinasi antara proses dari \\
daninformasi di seluruh perusahaan. & perusahaan dalam bussiness pipeline, mulai dari \\
& pemasok sampai kepada pelanggan. \\
\hline
\end{tabular}

\subsection{Jaringan Syaraf Tiruan}

Jaringan syaraf tiruan merupakan sistem pemroses informasi yang memiliki karakteristik mirip dengan jaringan syaraf biologi [6]. Jaringan syaraf tiruan merupakan sistem komputasi yang didasarkan atas pemodelan sistem syaraf biologis (neuron) melalui pendekatan dari sifat-sifat komputasi biologis (biological computation) [8][11]. Jaringan syaraf tiruan dibentuk sebagai generalisasi model matematika dari jaringan syaraf biologi dengan asumsi sebagai berikut :

1) Pemrosesan informasi terjadi pada banyak elemen sederhana (neuron).

2) Sinyal dikirimkan diantara neuron-neuron melalui penghubung- penghubung.

3) Penghubung antar neuron memiliki bobot yang akan memperkuat atau memperlemah sinyal. 
4) Untuk menentukan keluaran (output), setiap neuron menggunakan fungsi aktivasi yang dikenakan pada penjumlahan masukan (input) yang diterima. Besarnya keluaran (output) ini selanjutnya dibandingkan dengan suatu batas ambang [6]. Neuron adalah unit pemroses informasi yang menjadi dasar dalam pengoperasian jaringan syaraf tiruan [2].

Prinsip terpenting yang harus diperhatikan dalam sinkronisasi aktivitas-aktivitas sebuah supply chain adalah menciptakan hasil yang lebih besar, tidak hanya bagi tiap anggota rantai tetapi bagi keseluruhan sistem. Kesuksesan implementasi dari prinsip ini membutuhkan perubahan- perubahan pada tingkatan strategis maupun taktis. Berikut 7 prinsip Supply Chain Management untuk membantu para manajer dalam merumuskan strategi pelaksanaan Supply Chain Management[1][2], yaitu:

1) Segmentasi pelanggan berdasarkan kebutuhannya.

2) Sesuaikan jaringan logistik untuk melayani kebutuhan pelanggan yang berbeda.

3) Dengarkan signal pasar dan jadikan signal tersebut sebagai dasar dalam perencanaan kebutuhan (demandplanning) sehingga bisa menghasilkan ramalan yang konsisten dan alokasi sumber daya yang optimal.

4) Diferensiasi produk pada titik yang lebih dekat dengan konsumen dan percepat konversinya di sepanjang rantai supply.

5) Kelola sumber-sumber supply secara strategis untuk mengurangi ongkos kepemilikan dari material maupun jasa.

6) Kembangkan strategi teknologi untuk keseluruhan rantai supply yang mendukung pengambilan keputusan berhirarki serta berikan gambaran yang jelas dari aliran produk, jasa, maupun informasi.

Adopsi pengukuran kinerja untuk sebuah supplychain secara keseluruhan dengan maksud untuk meningkatkan pelayanan kepada konsumen akhir

\section{METODOLOGI PENELITIAN}

Dengan metode Artificial Neural Network ( Jaringan Syaraf Tiruan ) yang diterapkan dalam salah satu aktifitas logistik, yaitu permalan ( forecasting ), maka prediksi pemenuhan kebutuhan (Demand) masyarakat akan Beras diharapkan dapat diselesaikan dengan optimal dikarenakan sifat dari metode ini yang fleksibel tanpa perlu mengklasifikasikan atau menginterpretasikan terlebih dahulu pola data historik yang ada. Fleksibelitas metode Artifical Neural Network itu disebabkan oleh keunggulan metode ini yang dapat mengenali pola suatu data historik pada saat pembentukan jaringannya dengan cara proses pembelajaran dan pelatihan (self learning ). Lebih tepatnya metode Neural Network (Jaringan Syaraf Tiruan) yang diterapkan adalah Backpropagation.

\subsection{Metode Pengumpulan Data}

Dalam penelitian ini untuk mendapatkan data-data yang diperlukan penulis menggunakan beberapa metode pengumpulan data sebagai berikut:

1) Data Primer

Data primer diperoleh melalui pengamatan secara langsung mengenai mekanisme pengadaan hingga pemasokan beras, pengadaan dan jumlah permintaan

2) Data Sekunder

Data Sekunder diperoleh dari penelitian lainnya yang relevan dengan penelitian ini.

\subsection{Metode Pengolahan Awal Data}

Data yang digunakan adalah data pasokan beras tahun 2008-2011, data terdiri dari jumlah pasokan per bulan. Untuk Pengolahan data awal pasokan beras dapat dilihat pada Tabel 2, berikut: 
Tabel 2. Pengolahan data awal pasokan beras

\begin{tabular}{llrrrr}
\hline & & \multicolumn{4}{c}{ Tahun } \\
\cline { 3 - 6 } No & Bulan & $\mathbf{2 0 1 1}$ & $\mathbf{2 0 1 0}$ & $\mathbf{2 0 0 9}$ & \multicolumn{1}{c}{$\mathbf{2 0 0 8}$} \\
\cline { 3 - 6 } & & Jumlah & Jumlah & Jumlah & Jumlah \\
\hline 1 & Januari & 678 & 467 & 943 & 643 \\
2 & Februari & 4455 & 3176 & 12564 & 10564 \\
3 & Maret & 8567 & 5243 & 15634 & 13134 \\
4 & April & 11666 & 10652 & 22121 & 17121 \\
5 & Mei & 5338 & 4652 & 13834 & 10834 \\
6 & Juni & 2783 & 1373 & 7840 & 7840 \\
7 & Juli & 771 & 587 & 964 & 664 \\
8 & Agustus & 4322 & 3175 & 12874 & 9874 \\
9 & September & 8446 & 5043 & 16433 & 12133 \\
10 & Oktober & 8702 & 5243 & 16822 & 12222 \\
11 & November & 10423 & 8343 & 20150 & 16150 \\
12 & Desember & 6250 & 4356 & 17821 & 11821 \\
\hline
\end{tabular}

\subsection{Proses Transformasi Data}

Untuk proses transformasi data awal pasokan beras dapat dilihat pada Tabel 3, berikut:

Tabel 3. Proses tranformasi data awal pasokan beras

\begin{tabular}{ccccccc}
\hline \multirow{2}{*}{ Tahun } & Januari & Februari & Maret & April & Mei & Juni \\
\hline \multirow{2}{*}{2008} & 0.106502 & 0.47303 & 0.567978 & 0.715277 & 0.483005 & 0.372393 \\
& Juli & Agustus & September & Oktober & November & Desember \\
& 0.107278 & 0.447539 & 0.530997 & 0.534285 & 0.679403 & 0.51947 \\
\multirow{2009}{*200}{} & Januari & Februari & Maret & April & Mei & Juni \\
& 0.117586 & 0.54692 & 0.66034 & 0.9 & 0.593839 & 0.372393 \\
& Juli & Agustus & September & Oktober & November & Desember \\
& 0.118362 & 0.558373 & 0.689859 & 0.70423 & 0.827182 & 0.741138 \\
& Januari & Februari & Maret & April & Mei & Juni \\
& 0.1 & 0.200083 & 0.276448 & 0.476282 & 0.254613 & 0.133472 \\
& Juli & Agustus & September & Oktober & November & Des \\
& 0.104433 & 0.200046 & 0.269059 & 0.276448 & 0.390976 & 0.243678 \\
& Januari & Februari & Maret & April & Mei & Juni \\
& 0.107795 & 0.247335 & 0.399252 & 0.513743 & 0.279958 & 0.185564 \\
& Juli & Agustus & September & Oktober & November & Desember \\
& 0.111231 & 0.242422 & 0.394782 & 0.404239 & 0.467821 & 0.313651 \\
\hline
\end{tabular}

\subsection{Eksperimen dan Pengujian Metode}

Dalam bagian ini akan melakukan pengujian terhadap data pasokan beras tahun 2008 yang mana datanya akan di uji melalui tahap-tahap atau langkah-langkah dari algoritma. Transformasi data awal pada tahun 2008 dapat dilihat pada Tabel 4, berikut ini: 
Tabel 4. Transformasi data awal pasokan beras tahun 2008

\begin{tabular}{ccccccc}
\hline Tahun & Januari & Februari & Maret & April & Mei & Juni \\
\hline \multirow{2}{*}{2008} & 0.106502 & 0.47303 & 0.567978 & 0.715277 & 0.483005 & 0.372393 \\
& Juli & Agustus & September & Oktober & $\begin{array}{c}\text { Novemb } \\
\text { er }\end{array}$ & $\begin{array}{c}\text { Desember } \\
\end{array}$ \\
\cline { 2 - 6 } & 0.107278 & 0.447539 & 0.530997 & 0.534285 & 0.679403 & 0.51947 \\
\hline
\end{tabular}

Pada eksperimen proses transformasi ke dalam metode backpropagation bias dilihat pada Tabel 5.

Tabel 5. Proses transformasi data ke dalam backpropagation

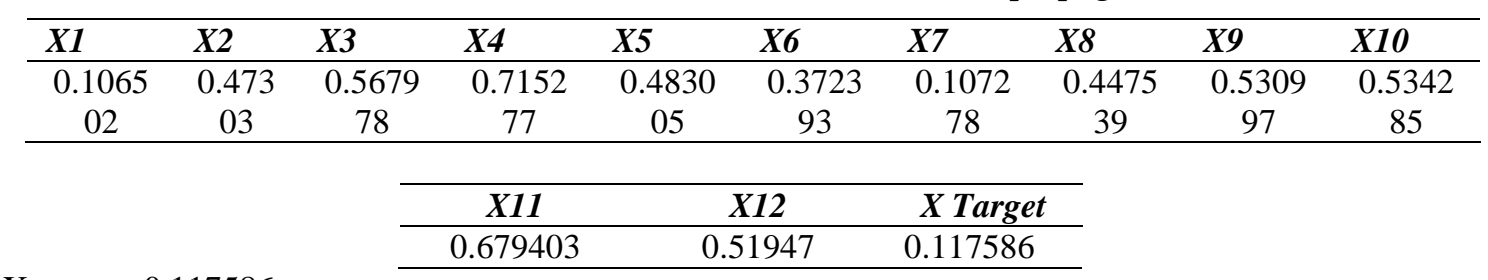

Xtarget $=0.117586$

$\alpha=0.3$

1) Langkah 0:

Inisialisasi semua bobot dengan bilangan acak kecil:

\begin{tabular}{cccc}
\hline & $\boldsymbol{Z}_{\boldsymbol{1}}$ & $\boldsymbol{Z}_{\mathbf{2}}$ & $\boldsymbol{Z}_{\mathbf{3}}$ \\
\hline 1 & 0.1 & 0.3 & -0.1 \\
$\mathrm{X}_{1}$ & 0.5 & 0.1 & -0.5 \\
$\mathrm{X}_{2}$ & -0.2 & 0.1 & 0.2 \\
$\mathrm{X}_{3}$ & 0.1 & -0.2 & -0.3 \\
$\mathrm{X}_{4}$ & 0.3 & 0.1 & -0.1 \\
$\mathrm{X}_{5}$ & -0.4 & 0.4 & 0.2 \\
$\mathrm{X}_{6}$ & 0.3 & 0.5 & -0.1 \\
$\mathrm{X}_{7}$ & 0.2 & 0.2 & -0.1 \\
$\mathrm{X}_{8}$ & -0.1 & -0.3 & 0.4 \\
$\mathrm{X}_{9}$ & 0.1 & 0.1 & -0.5 \\
$\mathrm{X}_{10}$ & 0.4 & -0.1 & -0.1 \\
$\mathrm{X}_{11}$ & -0.3 & 0.2 & 0.1 \\
$\mathrm{X}_{12}$ & 0.2 & 0.3 & -0.2 \\
\hline
\end{tabular}

2) Langkah 1

Jika kondisi penghentian belum terpenuhi, lakukan langkah 2 sampai dengan 8

3) Langkah 2

Untuk setiap pasang data pelatihan, lakukan langkah 3 sampai dengan 8

\section{Fase I: Propagasi Maju}

4) Langkah 3

Tiap unit masukkan menerima sinyal dan meneruskan ke unit tersembunyi

5) Langkah 4

Hitung semua keluaran di unit tersembunyi ( $\mathrm{Zj})$ :

$Z n e t j=v_{j 0}+\sum^{n} x i v_{j i}$

$Z_{n e t j}=v_{10}+\Sigma^{2} x i v_{j i}$ 
Znet1 $=\mathrm{v} 1-0+\mathrm{x} 1 . \mathrm{v} 1-1+\mathrm{x} 2 . \mathrm{v} 1-2+\mathrm{x} 3 . \mathrm{v} 1-3+\mathrm{x} 4 . \mathrm{v} 1-4+\mathrm{x} 5 . \mathrm{v} 1-5+\mathrm{x} 6 . \mathrm{v} 1-6+\mathrm{x} 7 . \mathrm{v} 1-7+\mathrm{x} 8 . \mathrm{v} 1-8+\mathrm{x} 9 . \mathrm{v} 1-9$ $+\mathrm{x} 10 . \mathrm{v} 1-10+\mathrm{x} 11 . \mathrm{v} 1-11+\mathrm{x} 12 \cdot \mathrm{v} 1-12$

$=0.1+0.106502 \cdot 0.5+0.47303 \cdot-0.2+0.567978 \cdot 0.1+0.715277$.

$0.3+0.483005$. $-0.4+0.372393 .0 .3+0.107278 .0 .2+0.447539$.

$-0.1+0.530997 .0 .1+0.534285 .0 .4+0.679403 .-0.3+0.51947 .0 .2$

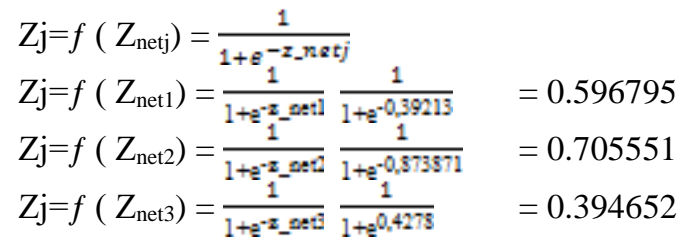

6) Langkah 5

Hitung semua jaringan di unit keluaran $\left(\mathrm{y}_{\mathrm{k}}\right)$

$$
\begin{aligned}
& y_{-} n \theta t_{k}=w_{k 0}+\sum_{j=1}^{p} z_{j} w_{k j} \\
& y_{\text {net }{ }_{1}}=w_{10}+\sum_{j=1}^{p} z_{j} w_{k j}=w_{0}+z_{1} w_{1}+z_{2} w_{2}+z_{a} w_{a} \\
& =-0,1+0.596795 .0,2+0.705551 \cdot 0,1+0.394652 .(-0,4) \\
& =-0.0679467 \\
& y_{1}=f\left(y_{-} \text {net }_{k}\right)=\frac{1}{1+n^{-y} \text { nat }_{k}} \\
& =\frac{1}{1+-0.0679467}=0.51698
\end{aligned}
$$

\section{Fase II : Propagasi Mundur}

7) Langkah 6

$$
\begin{aligned}
\delta_{\mathrm{k}}=\left(\mathrm{t}_{\mathrm{k}}-\mathrm{y}_{\mathrm{k}}\right) \mathrm{f}^{\prime} & \left(\mathrm{y} \_n e \mathrm{t}_{\mathrm{k}}\right)=\left(\mathrm{t}_{\mathrm{k}}-\mathrm{y}_{\mathrm{k}}\right) \mathrm{y}_{\mathrm{k}}\left(1-\mathrm{y}_{\mathrm{k}}\right) \\
\delta_{1}=\left(\mathrm{t}_{1}-\mathrm{y}_{1}\right) \mathrm{f}^{\prime} & \left(\mathrm{y} \operatorname{lnet}_{1}\right)=\left(\mathrm{t}_{1}-\mathrm{y}_{1}\right) \mathrm{y}_{1}\left(1-\mathrm{y}_{1}\right) \\
& =(0.117586-0.51698) 0.51698(1-0.51698) \\
& =-0.0997333 \\
62 & =(0.54692-0.51698) 0.51698(1-0.51698) \\
& =0.00747637 \\
63 & =(0.66034-0.51698) 0.51698(1-0.51698) \\
& =0.0357987 \\
64 & =(0.9-0.51698) 0.51698(1-0.51698) \\
& =0.0956446
\end{aligned}
$$

Misal dengan menggunakan $\alpha=0,3$

$$
\begin{aligned}
\Delta \mathrm{w}_{\mathrm{kj}} & =\alpha \delta_{\mathrm{k}} \mathrm{Z}_{\mathrm{j}} \\
\Delta \mathrm{w}_{10} & =\alpha \delta_{1}(1) \\
& =0,3 .(-0.0997333) .(1)=-0.02992
\end{aligned}
$$

Dengan cara yang sama maka :
$\Delta \mathrm{W} 0=-0.02992$
$\Delta \mathrm{W} 1=0.00224291$
$\Delta \mathrm{W} 2=0.0107396$
$\Delta \mathrm{W} 3=0.0286934$ 
8) Langkah 7

Hitung factor $\delta$ unit tersembunyi berdasarkan kesalahan di setiap unit tersembunyi zj $(\mathrm{j}=1,2,3, \ldots, p)$

$$
\begin{array}{ll}
\delta_{\text {net }_{1}}=\sum_{k=1}^{m} \delta_{k} w_{j} \\
\delta_{\text {net }_{1}}=\delta_{1} \mathrm{~W}_{11=} & (-0,0997333) .0,00224291=-0.000223693 \\
\delta_{\text {net }_{2}}=\delta_{2-} \mathrm{W}_{12}= & 0.00747637 .0 .0107396=0.0000802932 \\
\delta_{\text {neta }_{2}}=\delta_{3} \mathrm{~W}_{13}= & 0.0357987 .0 .0286934=0.00102719
\end{array}
$$

Faktor kesalahan ô unit tersembunyi

$$
\begin{aligned}
& \delta j=\delta \_n e t j f^{\prime}\left(z \_n e t j\right)=\delta \_ \text {net } z j(1-z j) \\
& \delta 1=\bar{\delta} \text { net } \mathrm{z} 1(\overline{1}-\mathrm{z} 1) \\
& =(-0,000223693) \cdot 0,596795 .(1-(0,596795))=-0.0000538274 \\
& \delta 2=\delta \text { net } \mathrm{z} 2(1-\mathrm{z} 2) \\
& =0,0000802932.0,705551 .(1-(0,705551))=0.0000166808 \\
& \delta 3=\delta \text { net } \mathrm{z} 3(1-\mathrm{z} 3) \\
& =0,00102719.0,394652 .(1-(0,394652))=0.000245398 \\
& \Delta \mathrm{vji}=\alpha \delta \mathrm{j} . \mathrm{xi} \\
& \Delta \mathrm{v} 10=\alpha \delta 1=0,3 .(-0,0000538274) .1=-0.0000161482 \\
& \Delta \mathrm{v} 20=\alpha \delta 2=0,3 .(0,0000166808) .1=0.00000500424 \\
& \Delta \mathrm{v} 30=\alpha \delta 3=0,3 .(0,000245398) .1=0.0000736194
\end{aligned}
$$

\section{Fase III : Perubahan Bobot}

Perubahan bobot garis yang menuju unit keluaran

$w k j($ baru $)=w k j($ lama $)+\Delta w k j$

$\mathrm{w} 10$ (baru) $=\mathrm{w} 10($ lama $)+\Delta \mathrm{w} 10=-0,1-0.02992=-0.12992$

$\mathrm{w} 11($ baru $)=\mathrm{w} 11($ lama $)+\Delta \mathrm{w} 11=0,2+0.00224291=0.202243$

$\mathrm{w} 12($ baru $)=\mathrm{w} 12($ lama $)+\Delta \mathrm{w} 12=0,1+0.0107396=0.11074$

$\mathrm{w} 13($ baru $)=\mathrm{w} 13($ lama $)+\Delta \mathrm{w} 13=-0,4+0.0286934=-0.371307$

$$
\begin{aligned}
\mathrm{Vji}(\text { baru }) & =\mathrm{vji}(\text { lama })+\Delta \mathrm{vji} \\
\mathrm{V} 1-0(\text { baru }) & =\mathrm{v} 1-0(\text { lama })+\Delta \mathrm{v} 1-0 \\
& =0,1-0.0000161482=0.0999839 \\
\mathrm{~V} 2-0(\text { baru }) & =\mathrm{v} 1-0(\text { lama })+\Delta \mathrm{v} 1-0 \\
& =0,1+0.00000500424=0.100005 \\
\mathrm{~V} 3-0 \text { (baru) } & =\mathrm{v} 1-0(\text { lama })+\Delta \mathrm{v} 1-0 \\
& =0,1+0.0000736194=0.100074
\end{aligned}
$$

\section{HASIL DAN PEMBAHASAN}

\subsection{Algoritma Pembelajaran Backpropagation}

Proses awal dari algoritma pembelajaran Backpropagation adalah menentukan arsitektur jaringan. Model arsitektur jaringan pada kasus ini dapat dilihat pada Gambar 1, berikut:

1) Menentukan Arsitektur Jaringan

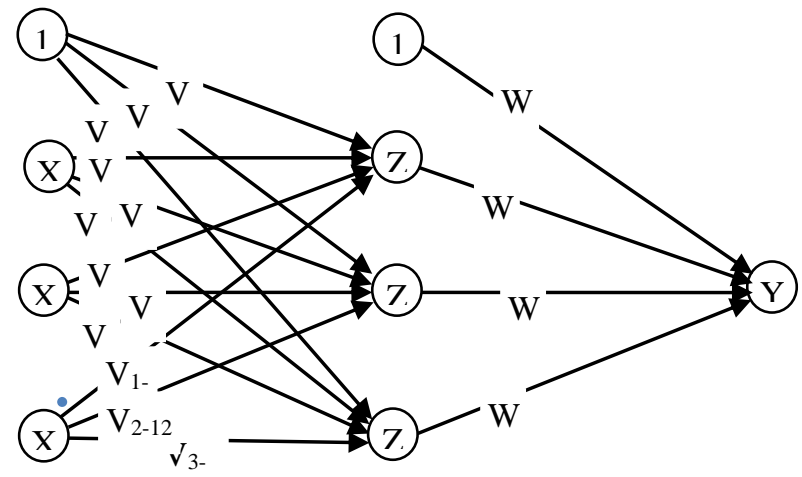

Gambar 1. Arsitektur Jaringan 
2) Menentukan besarnya $\alpha=0,3$

3) Menentukan besarnya error $=10-5=0,00005$

4) Menentukan besarnya epoch $=1000$

5) Menentukan fungsi aktifasi=sigmoid biner

6) Menentukan data pelatihan

Tabel 4. Nilai a $\&$ b pelatihan penyaluran

\begin{tabular}{cc}
\hline $\boldsymbol{a}$ & $\boldsymbol{b}$ \\
\hline 22121 & 467 \\
\hline
\end{tabular}

Nilai a \& b pelatihan penyaluran dapat dilihat pada Tabel 4. Jika fungsi aktivasi dengan menggunakan sigmoid biner (range 0 sampai dengan 1), maka data harus ditransformasikan [0,1]. Tapi akan lebih baik di transformasikan pada range $[0,10,9]$ karena fungsi sigmoid nilainya tidak pernah 0 ataupun 1 .

Untuk mentransformasikan dengan rumus :

$$
\mathrm{X}^{\prime}=\frac{0,8(x-a)}{n-\pi}+0,1
$$

Keterangan:

$\mathrm{X}^{\prime} \quad=$ Hasil Transformasi

$\mathrm{x} \quad=$ Data awal

a = Nilai Minimal data awal

$\mathrm{b} \quad=$ Nilai maximal data awal

\subsection{Uji Akurasi}

Pengujian uji akurasi menggunakan Software data mining yaitu Rapidminer, untuk uji pertama melalui data sample yaitu data pasokan tahun 2008-2011, pada bagian bulan akan dihilangkan untuk mendapatkan akurasi yang lebih tinggi, target dijadikan sebagai label dalam rapidminer sehingga untuk hasilnya menggunakan software rapidminer bisa dilihat pada gambar 2, berikut :

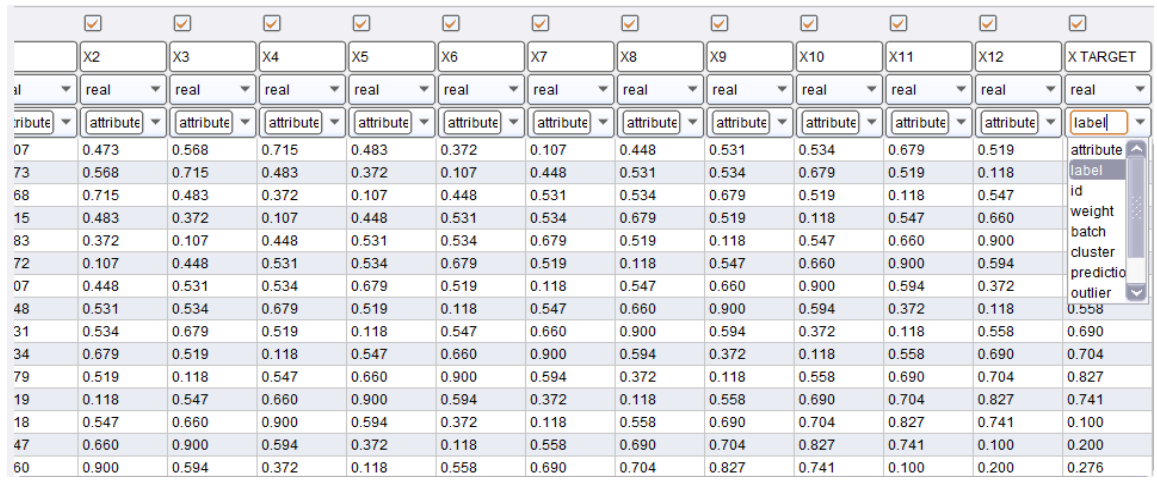

Gambar 2. Proses Pemberian Label Untuk Uji Akurasi

\subsection{Uji Validasi}

Untuk pengujiannya menggunakan Software data mining yaitu Rapidminer, untuk uji pertama melalui data hasil transformasi dari data pengadaan beras tahun 2008-2011. Sehingga muncul pola sebanyak 36 dan terdiri dari 12 bulan. Target dari masing-masing bulan di ubah attributnya menjadi label supaya tingkat errornya kecil. Proses import data dan validasi dapat lihat pada Gambar 3, serta untuk proses validasi dengan rapidminer menggunakan neural network dapat dilihat pada Gambar 4 .

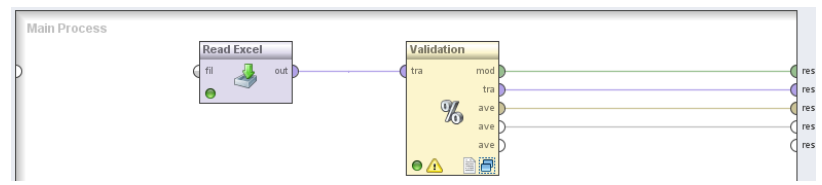

Gambar 3. Proses Import Data Dan Validasi 


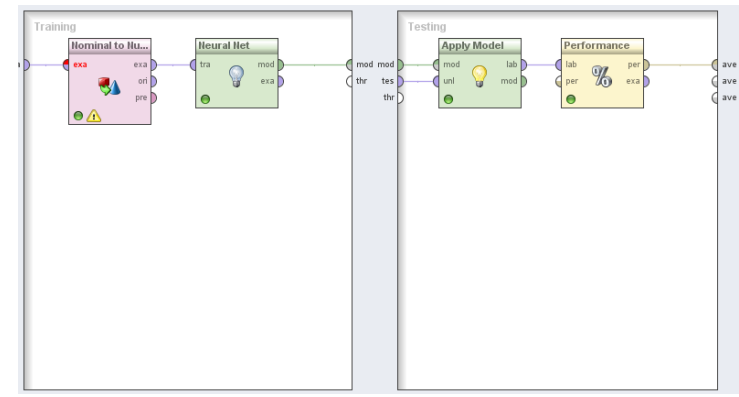

Gambar 4. Proses Validasi Dengan Rapidminer Menggunakan Neural Network

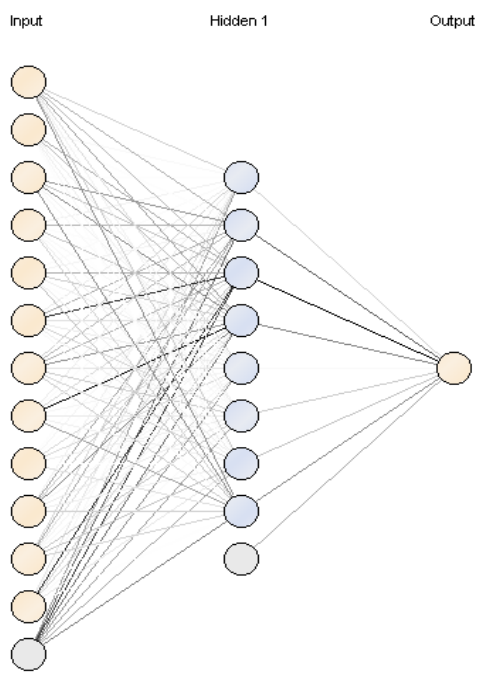

Gambar 4. Arsitektur Backpropagation Rapidminer

Arsitektur Backpropagation Rapidminer dapat dilihat pada Gambar 4. Pada Gambar 4 tersebut terdapat 13 input, 1 bias dan terdapat 9 hidden layer, pada output terdapat 1 yaitu besarnya prediksi data beras tahun berikutnya.

Tabel 5. Penenentuan error

\begin{tabular}{cccl}
\hline Training cycles & Learning rate & Momentum & Root MSE \\
\hline 500 & 0,3 & 0,2 & 0,226 \\
500 & 0,4 & 0,2 & 0,215 \\
500 & 0,5 & 0,2 & 0,217 \\
500 & 0,6 & 0,2 & 0,239 \\
500 & 0,7 & 0,2 & 0,227 \\
$\mathbf{5 0 0}$ & $\mathbf{0 , 8}$ & $\mathbf{0 , 2}$ & $\mathbf{0 , 2 1 2}$ \\
\hline
\end{tabular}

Dari hasil eksperimen uji training menunjukkan bahwa penentuan error pada Tabel 5, didapatkan root Mean Square error (MSE) terkecil yaitu dengan menggunakan Training cycles 500, Learning rate 0,8 dan momentum 0,2. 


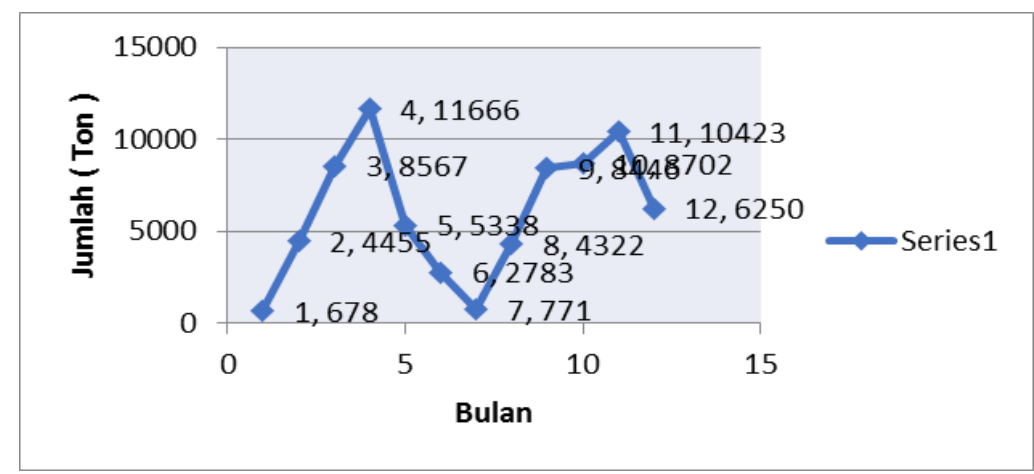

Gambar 5. Prediksi Pasokan Beras Pada Bulan Berikutnya

Prediksi pasokan beras pada bulan berikutnya dapat dilihat pada Gambar 5, menunjukkan bahwa menggunakan metode Artificial Neural Network (ANN) lebih baik dibandingkan metode yang sebelumnya. Pada penelitian ini dengan mengimplementasikan metode Artificial Neural Network (ANN) dalam forecasting maka masalah yang ada sudah bisa teratasi.

\section{KESIMPULAN}

Dari hasil penelitan di dapatkan data prediksi beras untuk tahun berikutnya dengan menggunakan Neural Network algoritma Backpropagation dengan Learning rate 0,8 dan momentum 0,2 mendapatkan paling kecil errornya. Dengan metode Artificial Neural Network (ANN) pola prediksi penentuan pengadaan beras tahun berikutnya menjadi lebih akurat.

\section{DAFTAR PUSTAKA}

[1] Ardiansyah. 2005. Manajemen Rantai Pasokan Penyediaan Barang (Supply Chain Management) Bagian Hulu Produk Susu Pasteurisasi [skripsi]. Bogor: Fakultas Pertanian, Institut Pertanian Bogor.

[2] Arisandi HS. 2006. Analisis Sistem Pasokan Buah-Buahan ke Ritel Modern dengan Supply Chain Management (Kasus PT. Moenaputra Nusantara, Pondok Melati, Bekasi). Bogor: Fakultas Pertanian, InstitutPertanian Bogor.

[3] Dewi, GC; E. Gumbira-Sa'id, dan I. Fahmi (2006). Faktor-Faktor yang Mempengaruhi Kinerja Rantai Pasokan Beras. Studi kasus di Perum Bulog, Jawa Barat. Jurnal Pangan Edisi no 46/XV/Januari 2006.

[4] Gumbira-Sa'id, E (2009). Kecenderungan Global Dan Visi Peningkatanan Ketahanan Pangan Melalui BULOG.FGD BULOG dan MB-IPB. Jakarta, 25Agustus 2009 IFPRI. 2009.

[5] Hermawan, Arief. 2006.Jaringan Saraf Tiruan,. Yogyakarta : ANDI.

[6] Jong Jek Siang. 2004. Jaringan Saraf Tiruan dan Pemrogramannya Menggunakan MATLAB. Yogyakarta: ANDI.

[7] Miranda,ST dan Drs.Amin Widjaja Tunggal Ak,MBA. (2007), Manajemen Logistik Dan

[8] Supply Chain Management. Jakarta: Harvarindo.

[9] Patuelli, R., A. Reggiani, P. Nijkamp, U. Blien. 2006. New Neural Network Methods for Forecasting Regional Employment. The Tinbergen Institute, The Institute for Economic Research of The Erasmus Universiteit Rotterdam, Universiteit van Amsterdam, and VrijeUniversiteit Amsterdam.

[10] Pujawan IN. 2005. Supply Chain Management Ed ke-1. Surabaya: GunaWidya

[11] Risyana W. 2008. Kinerja Supply Chain Management Komoditi Ayam Nenek (Grand Parent Stock Broiler) di PT. Galur Prima Cobbindo Sukabumi [skripsi]. Bogor: Fakultas Pertanian. Institut Pertanian Bogor.

[12] Sekarwati, Ade Kemal. 2004.Jaringan Syaraf Tiruan. (7 Juli 2006)

[13] Turban, E, Rainer Jr, R.K., Porter, R.E. (2001). Introduction to Information Technology.John wiley\& sons, USA.

[14] Van der Vorst. 2001.Enviromental Supply Chain Management: Using Life Cycle Assessment to Structure Supply Chains. Agribusiness Risk 1-13.

[15] Van der Vorst. 2006. Performance Measurement in Agri-Food Supply-Chain Networks: An Overview. Di dalam: Ondersteijn CJM, Wijnands RBM, Huirne\&Kooten Q, editor.Quantifying the Agri-Food Supply Chain.Belanda: Springer. hlm 13-24. 